\title{
Towards a European Refugee Policy
}

The refugee crisis is filled with drama and tragedy, but it is also an opportunity. It could provoke the European Union member countries to face reality and to accept that migration - and especially refugee - policies are no longer a competence that individual states can handle efficiently, ideally resulting in an agreement on a common EU migration and refugee policy.

The waiving of passport controls within the Schengen area and a common EU labour market with free movement of workers indispensably requires the same common rules for entrance to be applied everywhere at EU borders and an asylum procedure that follows the same standards in every member state. Otherwise, the deficiencies of nationally diverging migration or asylum regimes lead to an undesirable "triangle migration", with immigrants and refugees searching for the easiest entrance door. After entering, they can then move to whichever country they want, applying for asylum in the country with the most lenient rules. Once they have been granted the right to stay and work in that country, there are no further restrictions preventing them from migrating to any other EU country.

A quick look at the figures shows that there is indeed a need for common EU action. In 2015 Europe will record an unprecedented number of asylum seekers and refugees, with up to one million asylum applications - more than in any previous European refugee crisis since World War II. According to the German Federal Office for Migration and Refugees, Germany alone expects 800,000 asylum seekers in 2015 , which in absolute numbers would be the largest recorded annual inflow of people seeking asylum in any OECD country ever.

However, a Eurocentric view might neglect the fact that the largest migration flows currently take place within less developed global regions and within the area of the former Soviet Union. Turkey alone has received more than two million refugees from Syria, and over 300,000 people from Afghanistan, Iraq and Pakistan. Far more than a million Syrians are living in Lebanon and more than 600,000 in Jordan. The overwhelming burden of mass migration as a result of (civil) wars or economic grievances has to be borne by people in host countries, who often have little more than what they needed themselves to survive their everyday struggles.

Thus, the fears of some of the relatively wealthy EU members over the strong inflows of refugees seem overblown. Economic theory has clearly and conclusively demonstrated that unrestricted cross-border migration increases efficiency. As with free trade in goods, free migration of people is an absolute necessity in order to maximise global GDP. It equalises imbalances and enforces the welfare-improving "law of one price". Emigration reduces a surplus of workers in the regions of origin, and immigration removes a shortage of skilled workers in the destination countries. Therefore, open borders for all lead to greater prosperity for all.

Quite obviously, though, populations in many EU countries are concerned about the externalities related to immigration, such as the additional demand for public goods and infrastructure (e.g. schooling and education, healthcare) and from the impact on the social security system (healthcare, shelter and support payments). Furthermore, if the immigration inflows are quite large and the refugees differ profoundly in values, norms and behaviour from the host society, integration costs will be substantial - for both the host society and the refugees.

Externality costs might be lower than the economic efficiency gains. However, they dominate the discussion in the EU and explain why many see the inflow of refugees as a cost rather than a benefit. While the upper class might profit from the positive impacts of an additional work force, the underclass might compete with the refugees directly for the same public goods and the same public budgets and transfer payments. This explains why the refugee crisis might split EU societies into two factions - one rather welcoming and the other rather defensive. 
How should Europe respond to the refugee crisis? It has to balance the complex field of tension between humanitarian obligations, economic costs and the social anxieties of the host societies. Europe, as a strong supporter of human rights, must uncompromisingly support a correct, fair and quick asylum procedure which grants shelter and support to anyone who has had to flee from political terrorism and despotic prosecution. Humanism does not stop at national borders. It is an obligation that is to be shouldered together by all EU countries. Therefore, it is appropriate to demand pan-European solidarity and to distribute the resulting costs evenly over the whole of Europe with a quota system.

Within the agreements and rules of the EU institutions, a common quota should be established that fairly distributes the burden and costs of the asylum procedure to all EU member states according to economic and demographic criteria. Seen from a purely economic point of view, it could be efficient to give individual countries the option to exempt themselves from hosting asylum seekers by paying a fee to those countries that would be providing the facilities. However, this might be politically and socially unacceptable and would have the likely negative consequence that large numbers of asylum seekers would end up in concentrated areas, which would discourage integration within local communities.

However, the mass of refugees searching for asylum in Europe has made it obvious that solving the refugee crisis on European soil is not feasible. Making border fences higher and immigration controls more stringent is the wrong approach, as it tackles the symptoms rather than the causes of the waves of refugees coming to Europe. Granting asylum helps many vulnerable people in emergency situations, but it does not stop dictators, despots and warlords from arbitrarily and coercively persecuting and torturing minorities, opponents and dissidents.

The key to solving the refugee crisis lies in the countries of origin - and, more precisely, in the hands of their political leaders. Governments have to be made responsible for preventing their citizens from becoming refugees! A sustainable solution of the refugee crisis is only possible if the causes of flight and expulsion, misery, and hardship are curbed or even eliminated. Therefore, this is first and foremost a matter for European foreign ministers and European development and cooperation experts more so than for the ministers of interior affairs.

The great difficulty lies in the fact that sustainable solutions cannot be implemented without the will and approval of the governments of the countries of origin. In order to convince governments or feudal rulers in refugee-producing countries to respect fundamental human rights, international cooperation is required. European policies should make use of economic incentives and sanctions to ensure the protection of minorities and prevent political or religious persecution.

It is self-evident that individual European countries are not powerful enough to bring such governments to the negotiating table on their own. A joint and common European migration and refugee policy approach is needed. This would also prevent national governments from attempting to free-ride and pass along the costs to their neighbours, for example by completely closing their borders to asylum seekers or forcing refugees to transit to a neighbouring EU country.

The era of national migration policies in Europe has expired. EU member states should view the refugee crisis as a chance for more and stronger joint and common activities in migration and refugee policies. The EU Commissioner for Migration, Home Affairs and Citizenship has to coordinate his efforts closely with the High Representative for Foreign Affairs and Security Policy and with the Commissioner for International Cooperation and Development. The joint efforts should aim to stop governments that produce refugees and to reward good governance.

Thomas Straubhaar, University of Hamburg, Germany; and Transatlantic Academy, Washington DC, USA.
The prevention of refugee movements will cost the EU a lot of money - far more than has hitherto been spent. Nevertheless, prevention is still much cheaper for all parties concerned than rolls of barbed wire and refugee camps throughout Europe. 